\title{
The prediction of the water source condition in Shandong Province in fifteen years
}

\author{
Long Fei ${ }^{1, a}$ \\ ${ }^{1}$ North China Electric Power University, Baoding 071000, China; \\ 7767645274@qq.com
}

Keyword: AHP Grey model Water resource Forecast

\begin{abstract}
For today' s water shortage problem exacerbated, I propose a water shortage degree evaluation index ACW from supply and demand aspects.And based on the indicator, we establish a prediction of water resources in shandong to see what the water resource will be after 15years. .
\end{abstract}

\section{Introduction}

This paper proposed a Grey model and an AHP model to forecast the water resource of Shandong in the 15 years later.we first use Grey model to predict the situation(such as :per capital fresh water,rainfall,amount of desalination,the degree of pollution,regional GDP,population growth) in the next 15 years.Then I speculate the condition of the water source in Shandong Province in fifteen years based on the AHP model and the prediction above.

\section{Basic Model}

\subsection{Analysis of the problem}

In order to show what the water situation will be in 15 years, we have collected the relevant data over the past ten years. Through visiting the official website of The National Bureau of Statistics of the People's Republic of China, we obtain these important statistics.

\subsection{The AHP model}

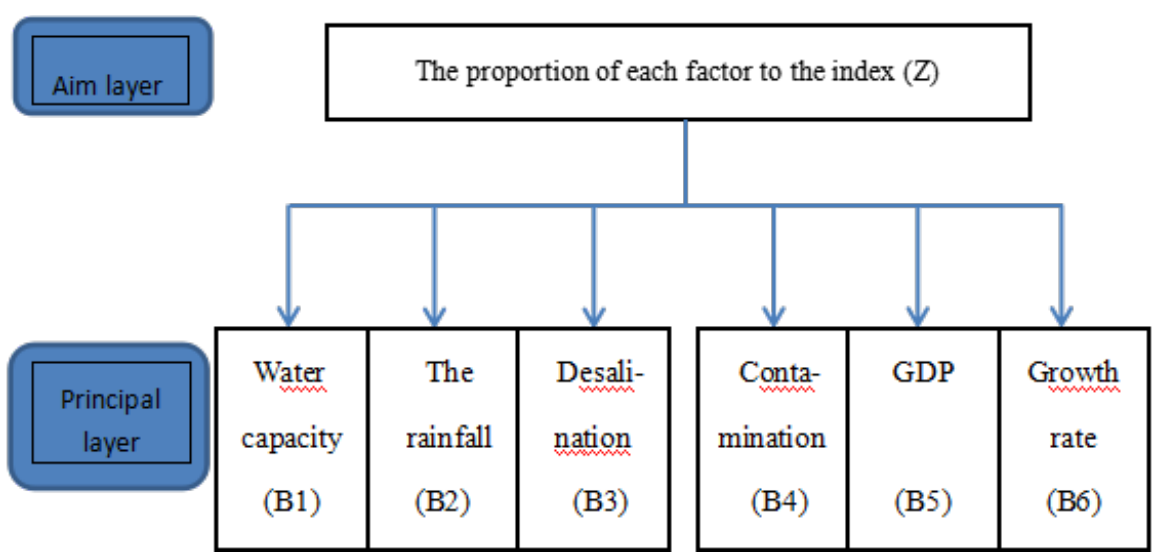

Fig1. Analytic hierarchy process modes The judgment matrix is as follow:

\begin{tabular}{|c|c|c|c|c|c|c|}
\hline Z & B1 & B2 & B3 & B4 & B5 & B6 \\
\hline B1 & 1 & $1 / 3$ & $1 / 9$ & $1 / 6$ & $1 / 3$ & $1 / 8$ \\
\hline B2 & 3 & 1 & $1 / 3$ & $1 / 2$ & 1 & $3 / 8$ \\
\hline B3 & 9 & 3 & 1 & $2 / 3$ & 3 & $9 / 8$ \\
\hline B4 & 6 & 2 & $3 / 2$ & 1 & 2 & $3 / 4$ \\
\hline B5 & 3 & 1 & $1 / 3$ & $1 / 2$ & 1 & $3 / 8$ \\
\hline B6 & 8 & $8 / 3$ & $8 / 9$ & $4 / 3$ & $8 / 3$ & 1 \\
\hline
\end{tabular}

Fig 2. The judgment matrix

The solution of the model 
$\mathrm{ACW}=0.0335 x_{1}+0.0998 x_{2}+0.3001 x_{3}+0.2001 x_{4}+0.0998 x_{5}+0.2667 x_{6}$

\subsection{Grey model}

-establishing the Grey differential equation:

$x_{i}^{(1)}(k)=\sum_{i=1}^{(k)} x_{i}^{0}(i), k=1,2,3 \ldots . . n$

$z_{i}^{(1)}=\left(z_{i}^{(1)}(2), z_{i}^{(1)}(3), \ldots \ldots \ldots z_{i}^{(1)}(n)\right)$

$x_{i}^{(0)}(k)+a z_{i}^{(1)}(k)=b, k=2,3,4 \ldots . . n$

-albinism differential equation:

$$
\frac{d x^{(1)}}{d t}+a x_{i}^{(1)}(t)=b
$$

Through the Least Squares, we get $\hat{a}, \hat{b}$ which are the parameters evaluation of $\mathrm{a}, \mathrm{b}$ $\hat{x}_{i}^{(1)}(k+1)=\left(x_{i}^{(0)}(1)-\frac{\hat{b}}{\hat{a}}\right) e^{-\hat{a} k}+\frac{\hat{b}}{\hat{a}}, \quad k=0,1, \cdots, n-1, \cdots$

-solution of the model:

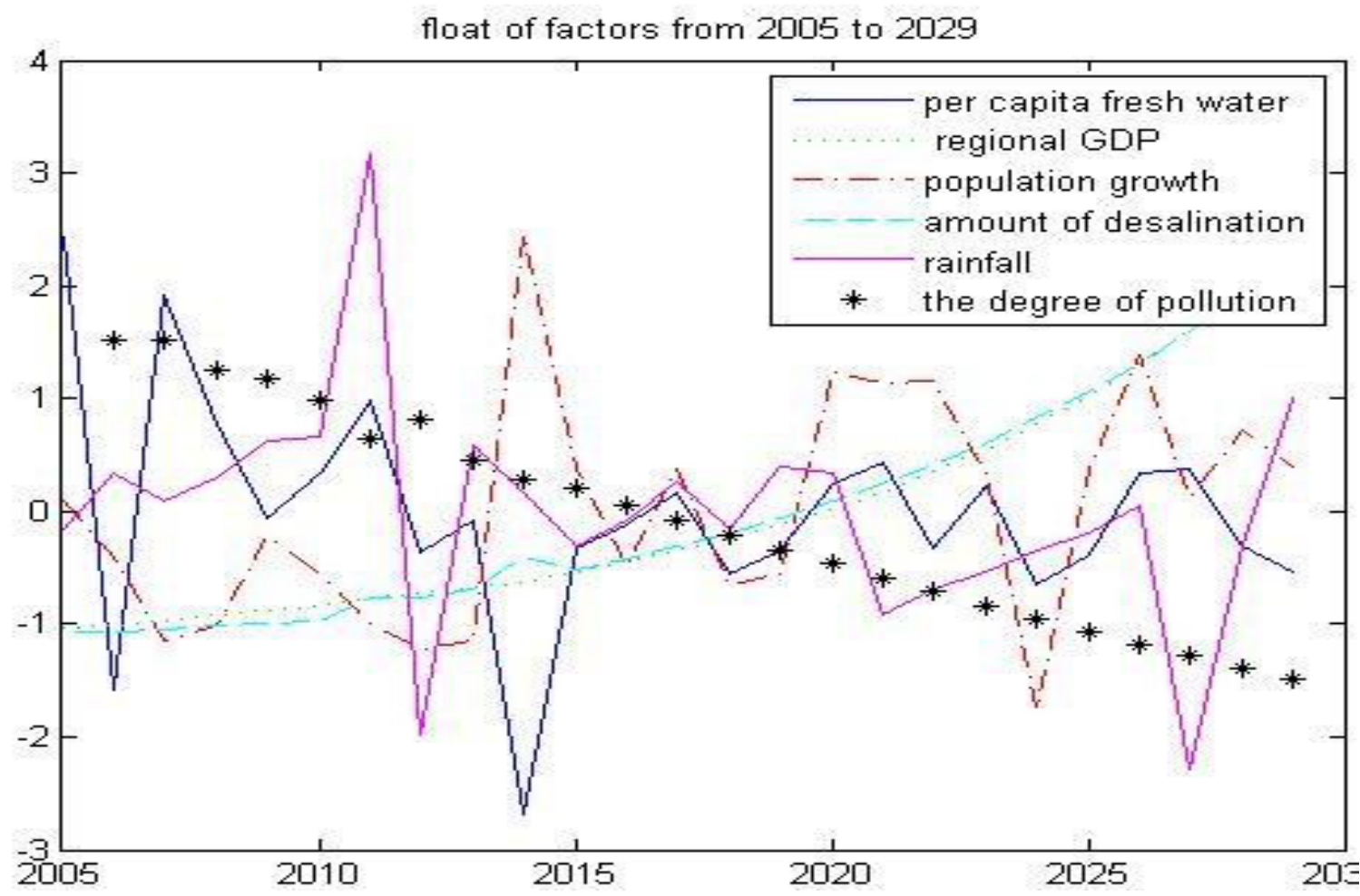

Fig 3. float of factors from 2005 to 2029

\subsection{The prediction based on the ACW.}

At now, there are already enough statistics about the six different factors from 2005 to 2029 which have been draw in the graph above and form a $25 \times 6$ matrix.Then, we orthonormalize the matrix. According to this, the ACW can be calculated:

$\mathrm{ACW}_{\mathrm{i}}=(0.178,0.4914,0.396,0.1825,0.2629,-0.7650,-0.668$,

$-0.1127,0.0776,0.1340,-0.2025,-0,-0.1191,-0.3042,-0$ )

（i=2005, 2029) 
According to $A C W_{i}$

we draw this diagram.

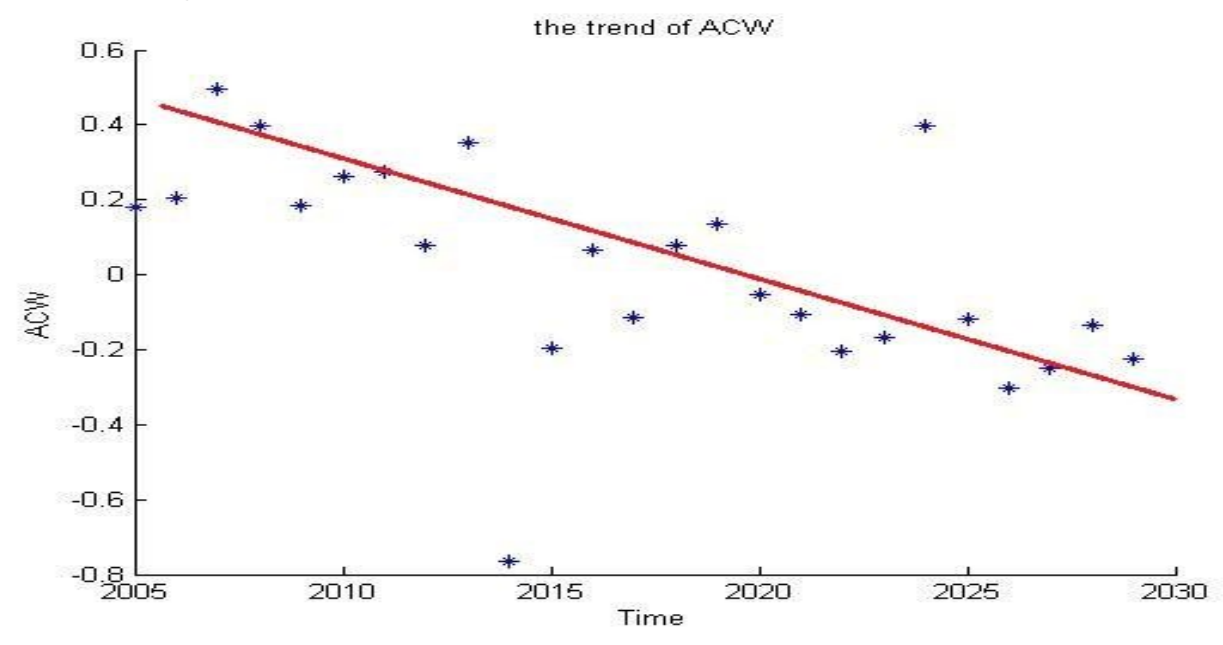

Fig 4. the trend of ACW

\section{Summary}

From the vivid picture (figure.3 and figure.4) and the models we have built, Some important information must be analyzed. As the ACW comes down gradually, the per capital fresh water decreases by degrees and the degree of contamination is being aggravated. But to get enough clean water, citizens may have to pay more debts to pure water company like Nongfu Spring Company, which will increase the cost of living

\section{References}

[1]Ling Zhang,Juncai Chen. Intervention in the application of travel demand forecasting model [J]. Jiangsu Commercial Forum,2007,05:81-83.

[2]Guangjuan Zhao. Business climate index intervention model research [D]. Central China Agricultural University,2011.

[3]Chengtao Zhu. Regional multi-objective optimization allocation of water resources research [D]. Hohai University,2006.

[2]Zhidong Shen. Using the analytic hierarchy process (ahp) construct the performance evaluation system of state-owned enterprises [J]. Audit research,2013,02:106-112. 